\title{
Endoscopic Management of Acquired Nasolacrimal Duct Obstruction Secondary to Radioactive Iodine Treatment for Thyroid Malignancy
} Vijay R. Ramakrishnan', Vikram D. Durairaj ${ }^{1,2}$ and Todd T. Kingdom ${ }^{1 *}$

${ }^{1}$ Department of Otolaryngology-Head \& Neck Surgery, University of Colorado Denver School of Medicine, Denver, Colorado, USA ${ }^{2}$ Department of Ophthalmology, University of Colorado Denver School of Medicine, Denver, Colorado, USA

\begin{abstract}
Introduction: Radioactive iodine (RAl) has been used in the management of thyroid malignancy for over 60 years. Established side effects of xerophthalmia, xerostomia, and sialadenitis are well known, and may occur in a dose-dependent manner. Acquired nasolacrimal duct obstruction (NLDO) has recently been described, with an estimated occurrence in $4 \%$ of patients receiving substantial doses of RAI for malignancy. To date, there are no published efforts of endoscopic management of this disease process.
\end{abstract}

Objectives: Given that thyroid malignancy and the use of RAl appear to be increasing in annual incidence, we aim to raise awareness of this common therapeutic side effect and to describe our success with endoscopic management of this condition.

Methods: Retrospective review of 5 patients (10 sides) treated for acquired NLDO secondary to RAI therapy. Subjective and objective outcomes were reviewed after powered endoscopic dacryocystorhinostomy (DCR).

Results: With a mean follow-up of 16.2 months, subjective assessment of epiphora and objective measurement of anatomic patency by saline irrigation and endoscopic visualization were recorded. Out of 10 procedures performed on 5 patients, subjective improvement and anatomic patency were achieved in 10/10 sides (100\%).

Conclusions: NLDO secondary to RAI therapy is a newly recognized phenomenon. Endoscopic management of this disease process has not been previously reported. Our results in a small cohort compare favorably to other treatment modalities in this patient population, and appear to be on par with success rates for this procedure in the general population. Physicians who manage patients with thyroid malignancy should be aware of this potential side effect of RAl therapy and understand the basics of its diagnosis and management.

Keywords: Dacryocystorhinostomy; Epiphora; Radioactive iodine; Endoscopic DCR; Thyroid

\section{Introduction}

Radioactive iodine (RAI) has been used in the treatment of thyroid malignancy for over 60 years. Several side effects of RAI administration are well known. Xerostomia occurs in roughly $50 \%$ of patients receiving $25-500 \mathrm{mCi}$, and is known to occur in a dose-dependent fashion [1]. Common ocular complications include chronic or recurrent conjunctivitis, dry eye syndrome, and xerophthalmia, which have been reported to occur in $23 \%$ of patients receiving radioiodine treatment for malignancy [2]. Recently, the association of $I^{131}$ treatment and nasolacrimal obstruction has been described $[3,4]$. In the updated report, 16 patients were found to have nasolacrimal duct obstruction (NLDO) occurring an average of 8.5 months after receiving moderateto-high cumulative doses of radioiodine $(200-951 \mathrm{mCi})$ for treatment of thyroid malignancy. Of a cohort of 612 patients receiving a minimum cumulative dose of $150 \mathrm{mCi}$, the authors found a $4.6 \%$ incidence of selfreported epiphora secondary to NLDO.

The incidence of thyroid malignancy has been escalating over the last three decades. According to the National Cancer Institute's Surveillance, Epidemiology, and End Results (SEER) program, the incidence of thyroid cancer has increased over 2.4-fold over the time period from 1973 to 2002 , now at 8.7 per 100,000 . This increase is primarily in the papillary histologic subtype (PTC). Simultaneously, the use of RAI in the treatment of PTC has increased, from less than $5 \%$ of cases in the 1960's to over 50\% since 1985 [5]. Currently, RAI has a large role in the long-term management of well-differentiated thyroid cancer, and its use may also be on the rise in years to come.
In the treatment of epiphora due to NLDO, many surgical techniques for dacryocystorhinostomy (DCR) have been described. Historically, the external approach has been considered the gold standard. However, there is now a body of literature validating the endoscopic approach to DCR with reported success rates comparable to external DCR [6-10]. The endoscopic approach to DCR offers several advantages: avoidance of an external incision and scar, preservation of the orbicularis oculi pump mechanism, preservation of medial canthal anatomy, improved visualization, decreased bleeding, decreased operative time, less postoperative pain, and the ability to address co-existing sinonasal disease. The pathophysiology of NLDO secondary to RAI use is still under investigation. To date, endoscopic management of RAI-induced NLDO has not been described. The objective of this study is to raise awareness of a manageable side-effect of a commonly used therapy, and to examine our results with a less invasive endoscopic surgical approach to treatment of this disease process.

Corresponding author: Todd T. Kingdom, MD, FACS, Department of Otolaryngology, University of Colorado School of Medicine, 12631 E. 17th Ave., B-205, Aurora, Colorado 80045, USA, Tel: 303-724 -1951; Fax: 303-724 -1961; E-mail: todd.kingdom@udenver.edu

Received March 31, 2011; Accepted May 25, 2011; Published June 04, 2011

Citation: Ramakrishnan VR, Durairaj VD, Kingdom TT (2011) Endoscopic Management of Acquired Nasolacrimal Duct Obstruction Secondary to Radioactive lodine Treatment for Thyroid Malignancy. J Aller Ther 2:110. doi:10.4172/21556121.1000110

Copyright: (C) 2011 Ramakrishnan VR, et al. This is an open-access article distributed under the terms of the Creative Commons Attribution License, which permits unrestricted use, distribution, and reproduction in any medium, provided the original author and source are credited. 
Citation: Ramakrishnan VR, Durairaj VD, Kingdom TT (2011) Endoscopic Management of Acquired Nasolacrimal Duct Obstruction Secondary to Radioactive lodine Treatment for Thyroid Malignancy. J Aller Ther 2:110. doi:10.4172/2155-6121.1000110

\section{Methods}

Adults confirmed to have RAI-induced NLDO undergoing powered endoscopic DCR from May 2003 to July 2007 were included in this study. Each patient underwent a preoperative evaluation including complete history and physical examination, probing of the canaliculi, lacrimal irrigation, and nasal endoscopy. Jones test, dacryocystography, and lacrimal scintigraphy were not used. A minimum of 6 months of postoperative follow-up was obtained in all patients. Septoplasty was performed when needed for surgical access; concurrent sinus surgery was not indicated in any patient.

All procedures were performed jointly between the otolaryngology (TTK) and ophthalmology (VDD) services according to a previously described technique [10]. Follow-up was obtained in postoperative clinic visits. Subjective outcomes analysis included the assessment of tearing at each post-operative visit. The presence of post-operative epiphora was recorded as complete resolution, mild post-operative epiphora, moderate post-operative epiphora, or no improvement. Anatomic patency was assessed by both irrigation of the lacrimal system and endoscopic visualization of free flow of tears from the neoostium. This study was approved by the Institutional Review Board of the University of Colorado Health Sciences Center.

\section{Surgical technique}

The surgical approach used has been discussed in detail in prior publications [10-12]. Briefly, an endonasal mucosal flap is elevated over the frontal process of the maxilla, and then trimmed with fine cutting forceps or a microdebrider. Thorough bone removal and lacrimal sac exposure is facilitated by use of a high-speed diamond burr. A lacrimal probe is inserted into either the upper or lower canalicular system to tent the medial wall of the lacrimal sac and verify adequate bone removal. The lacrimal sac is opened sharply both vertically and horizontally, creating anteriorly and posteriorly based flaps which are also trimmed. Dissection is sufficiently wide for complete visualization of the common internal punctum. Final lacrimal sac exposure may range from 10 to 20 $\mathrm{mm}$ in height and 10 to $15 \mathrm{~mm}$ in width. Silicone lacrimal intubation stents are passed and tied intranasally. Nasal packing was not used in this series.

\section{Results}

Five patients underwent bilateral procedures. The average age of the patient cohort was 46 years (range 23-77 years) and the female to male ratio was $3: 2$. The mean cumulative dose of radioactive iodine received was $474 \mathrm{mCi}$ (range 150-1400 mCi). Septoplasty was required for access in $80 \%(4 / 5)$ of patients. No additional sinus surgery was performed. Patient demographics are detailed in Table 1.

Mean follow-up was 16.2 months (range 6-48 months). Subjective improvement in epiphora was achieved in $100 \%(10 / 10)$ of procedures. Complete resolution of epiphora was obtained in $80 \%(8 / 10)$ of procedures, with two patients still having unilateral mild, intermittent tearing. One of these patients underwent subsequent lacrimal irrigation with total resolution of symptoms. Anatomic patency was confirmed by lacrimal irrigation and nasal endoscopy in 10/10 sides (100\%).

Silicone lacrimal stents were used in all cases. Stents were left in place as long as tolerated by the patient, with $20 \%(2 / 10)$ being removed due to patient discomfort. The remaining eight stents are currently in place. The two stents were removed at 4 months and 5 months postoperatively, and were not associated with continued symptoms or loss of anatomic patency. When removed, the procedure was performed in the office under topical anesthesia.

No major intraoperative or postoperative complications were encountered. One patient experienced mild postoperative infraorbital ecchymosis which resolved without intervention.

\section{Discussion}

Radioiodine has been used in the treatment of thyroid malignancy for over six decades. RAI can be given for ablation of residual thyroid tissue after total thyroidectomy to facilitate subsequent interpretation of serum thyroglobulin measurements, or to treat microscopic metastasis in high-risk groups. It may also be given in the setting of known residual tumor or distant metastasis. Activity levels for post-surgical ablation of remnant tissue are as low as $30 \mathrm{mCi}$, whereas in the case of distant metastatic disease, a total activity in the $100-600 \mathrm{mCi}$ range is ideally required for treatment $[13,14]$.

In patients given at least $150 \mathrm{mCi}, \mathrm{NLDO}$ is a newly recognized possible side effect. The causal relationship of radioactive iodine and NLDO was initially, and appropriately, questioned. It was thought that these patients were likely suffering from idiopathic NLDO similar to that found commonly in the middle-aged and elderly population. However, with case reports of patients as young as 16 years of age presenting with this disease process, a link has been acknowledged [15]. The mechanism by which RAI leads to NLDO is not completely understood. Human tears have been found to possess measurable amounts of radioiodine as quickly as 15 minutes after oral ingestion,

\begin{tabular}{|c|c|c|c|c|c|c|c|c|c|c|}
\hline Patient & Age $(y)$ gender & History & Cumulative rai dose (mci) & Side & Septoplasty & $f / u$ & Stent duration & Subjective tearing & $\begin{array}{l}\text { Objective } \\
\text { patency }\end{array}$ & Complications \\
\hline \multirow{2}{*}{1} & \multirow{2}{*}{43 female } & \multirow{2}{*}{ Papillary } & \multirow{2}{*}{370} & $\mathrm{~L}$ & Yes & $6 \mathrm{mos}$ & Still in & Complete resolution & Patent & None \\
\hline & & & & $\mathrm{R}$ & & $6 \mathrm{mos}$ & Removed at 4 mos & Complete resolution & Patent & None \\
\hline \multirow{2}{*}{2} & \multirow{2}{*}{41 male } & \multirow{2}{*}{ follicular } & \multirow{2}{*}{250} & $\mathrm{~L}$ & Yes & $\begin{array}{l}43 \\
\text { mos }\end{array}$ & Still in & Complete resolution & Patent & None \\
\hline & & & & $\mathrm{R}$ & & $\begin{array}{l}48 \\
\text { mos }\end{array}$ & Removed at 5 mos & Complete resolution & Patent & None \\
\hline \multirow{2}{*}{3} & \multirow{2}{*}{49 female } & \multirow{2}{*}{ follicular } & \multirow{2}{*}{150} & $L$ & Yes & 9 mos & Still in & Complete resolution & Patent & None \\
\hline & & & & $\mathrm{R}$ & & 9 mos & Still in & Complete resolution & Patent & None \\
\hline \multirow[b]{2}{*}{4} & \multirow[b]{2}{*}{77 male } & \multirow[b]{2}{*}{ follicular } & \multirow[b]{2}{*}{1400} & $\mathrm{~L}$ & No & $9 \mathrm{mos}$ & Still in & Complete resolution & Patent & None \\
\hline & & & & $\mathrm{R}$ & & 9 mos & Still in & Mild Intermittent & Patent & $\begin{array}{l}\text { Mild Ecchymosis, } \\
\text { Transient }\end{array}$ \\
\hline \multirow{2}{*}{5} & \multirow{2}{*}{23 female } & \multirow{2}{*}{ Papillary } & \multirow{2}{*}{200} & $\mathrm{~L}$ & Yes & $\begin{array}{l}12 \\
\text { mos }\end{array}$ & Still in & Complete resolution & Patent & None \\
\hline & & & & $\mathrm{R}$ & & $\begin{array}{l}12 \\
\mathrm{mos}\end{array}$ & Still in & $\begin{array}{l}\text { Mild Intermittent, } \\
\text { Improved with Irrigation }\end{array}$ & Patent & None \\
\hline
\end{tabular}

Table 1: Patient Demographics. 
Citation: Ramakrishnan VR, Durairaj VD, Kingdom TT (2011) Endoscopic Management of Acquired Nasolacrimal Duct Obstruction Secondary to Radioactive lodine Treatment for Thyroid Malignancy. J Aller Ther 2:110. doi:10.4172/2155-6121.1000110

Page 3 of 4

and have been cumulatively quantified at $0.01 \%$ of the oral dose of $\mathrm{I}^{123}$ at 4 hours post-ingestion [16]. When RAI is injected intravenously in a rat model, it has been shown to accumulate in several nonthyroidal tissues, including the nose and nasolacrimal duct [17].

Active uptake of iodine, either dietary or radioactive, is mediated by the sodium iodide symporter (NIS) in the basolateral membrane of follicular cells in the thyroid gland. This protein also exists in ductal cells of the salivary glands, and may be the source of pathophysiologic salivary gland side effects [18]. Recent study has demonstrated localized expression of the NIS protein in epithelial cells of the lacrimal sac and nasolacrimal duct, but not proximally in the canaliculi, conjunctiva or lacrimal gland. The authors theorize that $\mathrm{I}^{131}$ is actively accumulated in the lacrimal sac and nasolacrimal duct epithelium, resulting in fibrosis of the distal lacrimal system which manifests clinically as NLDO [19]. If the localization and disease manifestation is found in the lacrimal sac and nasolacrimal duct, sparing the proximal system, then endoscopic DCR should be a viable management option for this patient population.

This histologic finding may be clinically relevant in the case report of one patient who was found to have uptake in the medial orbit on a recombinant human thyroid-stimulating whole-body scan. After a complete examination, this patient was found to have NLDO secondary to RAI therapy 5 years earlier for papillary carcinoma. The patient underwent DCR with resolution of symptoms. Interestingly, the following Thyrogen-stimulated scan demonstrated resolution of uptake in the medial orbit. Histopathologic findings included fibrosis and foreign-body reaction in the setting of normal epithelium [20].

Although complete pathophysiologic understanding is lacking, physicians who treat patients with thyroid malignancy must be aware of this potential side effect of RAI therapy. In their series of ten patients, Kloos et al noted an 18 month delay in diagnosis from onset of symptoms [3]. In fact, $70 \%$ of these patients received some form of instructional or medical therapy without relief prior to examination and diagnosis. These patients were treated with balloon dilation, stent placement, external DCR, or conjunctival DCR, with $80 \%$ achieving complete or partial relief of symptoms. This group has estimated the incidence of RAI-induced NLDO in patients receiving a cumulative dose of at least $150 \mathrm{mCi}$ at $4.6 \%$ [4]. The true incidence in this patient population is unknown, and is likely higher than this figure given the lack of systematic screening in the study. Furthermore, it is possible that many patients experience partial or intermittent obstructive symptoms, and resolve without any intervention.

At this time, there has been no mention in the literature of the efficacy of endoscopic DCR for the treatment of RAI-induced NLDO. With a mean follow up of 16 months, our results are comparable to outcomes in the general population suffering from idiopathic acquired NLDO who undergo an identical procedure. Our experience in a small series of patients with RAI-induced NLDO indicates that endoscopic DCR is safe and efficacious when compared to other techniques.

\section{Conclusion}

NLDO secondary to RAI therapy is a newly recognized phenomenon, which may be going unrecognized in the majority of patients. The pathogenesis of this process is not entirely understood, but its diagnosis and management are similar to other forms of NLDO. Endoscopic treatment of this disease has not been previously reported. Our results in a small cohort compare favorably to other treatment modalities in this patient population, and appear to be on par with success rates for this procedure in the general population. Physicians who manage patients with thyroid malignancy should be aware of this potential side effect of RAI therapy and understand the basics of its diagnosis and management.

\section{Summary}

- The use of radioactive iodine has been recently associated with nasolacrimal duct obstruction.

The use of radioactive iodine for the management of well-differentiated thyroid cancer is greatly increasing.

If screened appropriately, epiphora secondary to radioactive iodine can be identified.

The true incidence is unknown, but is likely to be much greater than currently estimated given current lack of awareness of this entity.

The mechanism of this disease process is unknown.

Endoscopic dacryocystorhinostomy has comparable success to its external counterpart in a number of other disease processes.

Endoscopic dacryocystorhinostomy without surgical flaps is simple and safe and has excellent results in the treatment this disease process.

\section{References}

1. Solans R, Bosch JA, Galofre P, Porta F, Roselló J, et al. (2001) Salivary and lacrimal gland dysfuncion (sicca syndrome) after radioiodine therapy. J Nucl Med 42: 738-743.

2. Alexander C, Bader JB, Schaefer A, Finke C, Kirsch CM (1998) Intermediate and long-term side effects of high-dose radioiodine therapy for thyroid carcinoma. J Nucl Med 39: 1551-1554.

3. Kloos RT. Duvuuri V, Jhiang SM, Cahill KV, Foster JA, et al. (2002) Nasolacrimal drainage system obstruction from radioactive iodine therapy for thyroid carcinoma. J Clin Endo Met 87: 5817-5820.

4. Burns JA, Morgenstern KE, Cahill KV, Foster JA, Jhiang SM, et al. (2004) Nasolacrimal obstruction secondary to I(131) therapy. Ophthal Plast Reconstr Surg 20: 126-129.

5. Hay ID, Thompson GB, Grant CS, Bergstralh EJ, Dvorak CE, et al. (2002) Papillary Thyroid Carcinoma Managed at the Mayo Clinic during Six Decades (1940-1999): Temporal Trends in Initial Therapy and Long-term Outcome in 2444 Consecutively Treated Patients. World J Surg 26: 879-885.

6. Tsirbas A, Davis G, Wormald PJ (2004) Mechanical endonasa dacryocystorhinostomy versus external dacryocystorhinostomy. Ophthal Plast Reconstr Surg 20: 50-56

7. Ben Simon GJ, Joseph J, Lee S, Schwarcz RM, McCann JD, et al. (2005) External versus endoscopic dacryocystorhinostomy for acquired nasolacrimal duct obstruction in a tertiary referral center. Ophthalmology 112: 1463-1468.

8. Cokkeser Y, Evereklioglu C, Er H (2000) Comparative external versus endoscopic dacryocystorhinostomy: Results in 115 patients (130 eyes) Otolaryngol Head Neck Surg 123: 488-491.

9. Yigit O, Samancioglu M, Taskin U, Ceylan S, Eltutar K, et al. (2007) External and endoscopic dacryocystorhinostomy in chronic dacryocystitis: comparison of results. Eur Arch Otorhinolaryngol 264: 879-885.

10. Ramakrishnan VR, Hink EM, Durairaj VD, Kingdom TT (2007) Outcomes afte endoscopic dacryocystorhinostomy without mucosal flap preservation. Am J Rhinol 21: 753-757.

11. Wormald PJ (2002) Powered endoscopic dacryocystorhinostomy. Laryngoscope 112: 69-72.

12. Ramakrishnan VR, Durairaj VD, Kingdom TT. Principles of Revision Endoscopic Dacryocystorhinostomy. Operative Techniques in Otolaryngology (in press).

13. Barbaro D, Boni G, Meucci G, Simi U, Lapi P, et al. (2003) Radioiodine treatment with $30 \mathrm{mCi}$ after recombinant human thyrotropin stimulation in thyroid cancer: effectiveness for postsurgical remnants ablation and possible role of iodine content in L-thyroxine in the outcome of ablation. J Clin Endocrinol Metab 88 4110-4115.

14. Durante C, Haddy N, Baudin E, Leboulleux S, Hartl D, et al. (2006) Long-term outcome of 444 patients with distant metastases from papillary and follicular thyroid carcinoma: benefits and limits of radioiodine therapy. J Clin Endocrino Metab 91: 2892-2899. 
Citation: Ramakrishnan VR, Durairaj VD, Kingdom TT (2011) Endoscopic Management of Acquired Nasolacrimal Duct Obstruction Secondary to Radioactive lodine Treatment for Thyroid Malignancy. J Aller Ther 2:110. doi:10.4172/2155-6121.1000110

Page 4 of 4

15. Cetinkaya A, Kersten RC (2007) Relationship between radioactive iodine therapy for thyroid carcinoma and nasolacrimal drainage system obstruction. Ophth Plast Reconstr Surg 23: 496.

16. Bahkeet SMB, Hammami MM, Hemidan A, Powe JE, Bajaafar F (1998) Radioiodine secretion in tears. J Nucl Med 39: 1452-1454.

17. Leder $O$ (1982) The significance of extrathyroidal radioactive iodine accumulation and secretion in clinical pathology. Histochemistry 74: 585-588.

18. Jhiang SM, Cho JY, Ryu KY, DeYoung BR, Smanik PA, et al. (1998) An immunohistochemical study of $\mathrm{Na} / \mathrm{l}$ symporter in human thyoid tissues and salivary gland tissues. Endocrinology 139: 4416-4419.

19. Morgenstern KE, Vadysirisack DD, Zhang Z, Cahill KV, Foster JA, et al. (2005) Expression of Sodium lodide symporter in the lacrimal drainage system Implication for the mechanism underlying nasolacrimal duct obstruction in I131 treated patients. Ophthal Plast Reconstr Surg 21: 337-344

20. Shepler TR, Sherman SI, Faustina MM, Busaidy NL, Ahmadi MA, et al. (2003) Nasolacrimal duct obstruction associated with radioactive iodine therapy for thyroid carcinoma. Ophthal Plast Reconstr Surg 19: 479-481. 